\title{
Apricot pomaces extract (Prunus Armeniaca L.) as a highly efficient sustainable corrosion inhibitor for mild steel in sodium chloride solution
}

\author{
V.I. Vorobyova, ${ }^{1}$ M.I. Skiba ${ }^{2}$ and I.M. Trus ${ }^{2}$ \\ ${ }^{1}$ National Technical University of Ukraine "Igor Sikorsky Kyiv Polytechnic Institute", \\ Kyiv, Ukraine. Ave Peremogy 37, Kiev, 03056, Ukraine \\ ${ }^{2}$ Ukrainian State Chemical-Engineering University, Gagarin Ave. 8, Dnipro, 49005, \\ Ukraine \\ *E-mail: vorobyovavika1988@gmail.com
}

\begin{abstract}
The present study was carried out to identify the components present in the ethanol apricot pomace extract by GC-MS analysis. Various experimental models including iron(III) reducing capacity, total antioxidant capacity, DPPH radical scavenging activity were used for characterization of antioxidant activity of the extract. Weight loss investigation, potentiodynamic polarization, and FTIR techniques were used to study the corrosion inhibition. The maximum inhibition efficiency of $94.6 \%$ was achieved by using $500 \mathrm{ppm}$ of the inhibitor. Scanning electron microscopy (SEM) and atomic force microscopy (AFM) analysis were used to characterize the protective film. AFM also illustrated an improvement in the surface properties of the samples in the presence of APE. The influence of the immersion period on inhibition efficiency was evaluated. The GCMS experimental results show that the major compounds of the APE are 3,4,5trihydroxybenzoic acid, chlorogenic acid, 3-(3,4-dihydroxyphenyl)-2-propenoic acid, 2(3,4-dihydroxyphenyl)-3,5,7-trihydroxy-4H-chromen-4-one, and catechin. The results revealed that in the attendance of the APE and with the immersion time progress up to $48 \mathrm{~h}$, the inhibition capacity of inhibitor was promoted.The mechanism of action of the inhibitor is also discussed. Quantum chemical parameters calculated for the molecules contained in the aqueous extract are interpreted to predict the corrosion inhibition efficiency of the considered extract. The theoretical study gave insights to the active sites, chemical reactivity and possible interaction mechanism between the inhibitor compounds and mild steel surface. The apricot pomace extract studied in this work are potential multifunctional inhibition materials as they showed good antioxidant and anticorrosion properties.
\end{abstract}

Keywords: green corrosion inhibitors, antioxidant/free radical scavenging activity, phytochemicals, metals and alloys. 


\section{Introduction}

Nowadays, mild steel is known as the most famous alloy in a wide range of industrial applications such as metal processing, equipment, and construction [1-6]. Corrosion inhibitors are commonly used in industry to reduce the corrosion rate of metals and alloys. For mild steel protection in chloride-containing media, a large number of inorganic and organic corrosion inhibitors have been studied. The use of traditional corrosion inhibitors is now limited because of an increasing concept of "green chemistry" in the field of science, technology, and engineering [1-6]. This has prompted researchers to find out some cheap and effective "green" inhibitors [1,7-11]. Consequently, organic molecules extracted from food by-products appear as an alternative in the field of corrosion inhibition due to their biodegradability and easy availability. In this regard, the highly effective environmental friendly corrosion inhibitors obtained from natural products such as different parts of plants like root, seeds, leaves, stem, flower, and fruits are recently attracted the high consideration of the researchers. However, the inhibitor extracted from a waste without harm to plants and environment was seldom reported. Actually, in the present ecological context, plants, food, forest or agro-industrial wastes extracts appear as an alternative to fulfil the conditions of REACH regulation and European directives on the wastewater reject. The inhibition ability of the plant and agro-food wastes extracts is generally attributed to the presence of naturally phytochemical compounds which have antioxidant properties. It has also been found that plant components (biopolymers, proteins, flavonoids, and alkaloids) exhibit effective inhibitory activity based on their antioxidant activity derived from their structure. Importantly, the correlation between antioxidant/free radical scavenging activity of the extracts and the inhibition action was observed [12]. However, due to the large variety of molecules contained in natural extracts, the inhibition mechanisms remain largely unknown. So, it is an interesting and useful task to find new sources for highlighting anticorrosive and antioxidant active compounds and to obtain organic compounds for their further use as inhibitors of corrosion in the corrosive media. Apricot fruits (Prunus Armeniaca L.) are valued and highly consumed all over the world, both for their flavor and for nutritional qualities. Ukraine is one of the major apricot producers in the world with the approximate annual yield of 160000 tonnes/year of fresh fruit, seeds, and kernels, respectively.

Actually, apricot cake remaining after pressing of the fruit constitutes almost $60 \%$ of the total fruit mass [18]. The successful utilization of this natural waste may also provide an option for resource recovery. This waste is valuable since it is a rich source of the functional compound and can be used for corrosion inhibition of steel. In the literature, one can also find no information about possible applications of the apricot cakes and its extracted compounds for the development of corrosion inhibitor of mild steel in neutral media. The corrosion protection of mild steel in $1 \mathrm{M} \mathrm{H}_{3} \mathrm{PO}_{4}$ solution by apricot juice was studied only in one paper [13]. 
The aim of the present work firstly is to determine the chemical composition and antioxidant activities of apricot pomace extract (APE). Secondly, is to evaluate the corrosion inhibition effect of APE as "green" corrosion inhibitor of mild steel in neutral media and also investigate the constituents that provide inhibitive action of the extract.

\section{Materials and methods}

The apricot (Prunus Armeniaca L.) cultivar known under local name "Favorite" were harvested (during July 2019) in two geographical regions of Ukraine (Kherson, Nikolaev). The apricot pomace was supplied by an agro-food company (Vinni Frut) located in the city of Vinnytsia, Ukraine.

The mild strips were purchased from Rocholl, Aglasterhausen, Germany. Corrosion test samples (electrodes) were manufactured from mild steel St3 (European analog Fe37-3FN). The composition (wt. \%) of mild steel samples used in this study was as follows: $(93.9 \% \mathrm{Fe}, 1.2 \% \mathrm{P}, 1.1 \% \mathrm{Mn}, 1.0 \% \mathrm{Si}, 0.7 \% \mathrm{Cr}$ and $1.7 \% \mathrm{Ni})$.

Analytical grade ethanol (EtOH) and other chemicals were obtained from the general suppliers. All reagents were of analytical grade and were purchased from Sigma-Aldrich (Milan, Italy).

\subsection{Preparation of extract}

The apricot press pomace was obtained by cold pressing. The cake is made of pressed skins and pulp residues (of fresh apricots). The apricot press pomace extract was obtained with ethanol (EtOH) in a Soxhlet apparatus. The Soxhlet extraction was performed in the optimum condition. $5.0 \mathrm{~g}$ of ground material was extracted with $150 \mathrm{~mL} 95 \%$ ethanol in a Soxhlet apparatus for $2 \mathrm{~h}$. The solvent was removed at $40^{\circ} \mathrm{C}$ in a rotary vacuum evaporator under a nitrogen stream. $1 \mathrm{~g}$ of dry extract was dissolved in $100 \mathrm{~mL}$ ethanol to give a stock solution of $1 \%(\mathrm{w} / \mathrm{v})$ inhibitor. Then, appropriate volumes of $1 \%$ APE solution were added into the blank corrosive electrolyte $(0.5 \mathrm{M} \mathrm{NaCl})$ in order to obtain electrolytes containing different concentrations of APE in the range of 50-500 ppm.

\subsection{Identification of chemical profile}

\subsubsection{Gas chromatography-mass spectrometry (GC-MS)}

GC-MS analyses were carried out on a Varian 450-GC coupled to a Varian 220-MS IT (Agilent Technologies) through an electron impact (EI) ion source. A 5\%-phenyl-methyl polysiloxane (HP5MS) capillary column $(30 \mathrm{~m} \times 0.25 \mathrm{~mm}$ i.d., $0.25 \mu \mathrm{m})$ (Agilent Technologies) was used to separate the analytes, with $\mathrm{He}$ as a carrier gas at a flow rate of $1 \mathrm{~mL} / \mathrm{min}$. Oven temperature was initially kept at $140^{\circ} \mathrm{C}$ for $5 \mathrm{~min}$, ramped at $4{ }^{\circ} \mathrm{C} / \mathrm{min}$ to $310^{\circ} \mathrm{C}$ and held for $2.5 \mathrm{~min}$. A sample volume of $1 \mu \mathrm{L}$ was injected at a split ratio of 1:25. Injector and transfer line temperatures were $240^{\circ} \mathrm{C}$ and $290^{\circ} \mathrm{C}$, respectively. Spectra were recorded in full scan (from 50 to $600 \mathrm{~m} / \mathrm{z}$ ), with the EI source operating at a potential of $70 \mathrm{eV}$ in positive ion mode, and a source temperature of $200^{\circ} \mathrm{C}$. Instrument control and 
data processing for GC-MS analyses were done with MS Workstation v6.9.3 (Agilent Technologies) [19].The components were identified by comparing the peak retention time in the chromatogram and the complete mass-spectra of individual components with the corresponding results for pure compounds in the NIST-5 Mass Spectral Library [20]. The relative contents of the chemical components of the extract were found with the help of the method of internal normalization of the areas of peaks without correcting the sensitivity coefficients.

\subsubsection{Fourier transformation infrared spectroscopic studies (FTIR)}

For a better understanding of inhibition mechanism, the apricot cake extract was characterized through Fourier transform infrared spectroscopy (FTIR) in attenuated total reflection mode (Pike Technologies, GladiATR for FTIR with diamond crystal) in the range of $4000-400 \mathrm{~cm}^{-1}$.

\subsection{Antioxidant assays}

\subsubsection{Determination of total antioxidant capacity by phosphomolybdenum method}

The total antioxidant capacity of the extracts different solvents were evaluated by the phosphomolybdenum method as described by the method of Prieto et al. (1999) [21]. The analysis is based on the reduction of $\mathrm{Mo}(\mathrm{VI})$ to $\mathrm{Mo}(\mathrm{V})$ with an extract and, as a consequence, the formation of a green phosphate $/ \mathrm{Mo}(\mathrm{V})$ complex at acidic $\mathrm{pH}$. The volume of the extract to the reagent was $1: 10,0.5 \mathrm{~mL}$ of each sample solution and ascorbic acid $(100 \mu \mathrm{g} / \mathrm{mL})$ were taken for the experiment with $5 \mathrm{~mL}$ of reagent $(0.6 \mathrm{M}$ sulfuric acid, $28 \mathrm{mM}$ sodium phosphate and $4 \mathrm{mM}$ ammonium molybdate). The blank solution contained $5 \mathrm{~mL}$ of the reagent solution and the corresponding volume of the solvent used, which was used for the sample. All tubes were closed and incubated in a boiling water bath at $95^{\circ} \mathrm{C}$ for 90 minutes. After the samples had been cooled to room temperature, the absorbance of the solution of each sample was measured at $695 \mathrm{~nm}$ against the blank using a UV-Vis spectrophotometer (UV-5800PC spectrophotometer, FRU, China).

\subsubsection{Determination of antioxidant activity in terms of reducing power}

$\mathrm{Fe}(\mathrm{III})$ reduction is often used as an indicator of electron donating activity, which is an important indicator of the phenolic antioxidant effect [17]. Extracts, which have reduction potential, react with potassium ferricyanide $\left(\mathrm{Fe}^{3+}\right)$ to form potassium ferrocyanide $\left(\mathrm{Fe}^{2+}\right)$, which then reacts with ferric chloride to form a ferric ferrous complex that has an absorption maximum at $700 \mathrm{~nm}$. To prepare the reaction solution, a different amount of the extract, after the rotary evaporator, was mixed $(0.005 \mathrm{~g}, 0.01 \mathrm{~g}, 0.015 \mathrm{~g}, 0.02 \mathrm{~g}, 0.025 \mathrm{~g})$ was dissolved in an appropriate solvent $(1 \mathrm{~mL})$ and $1 \mathrm{~mL}$ phosphate buffer $(0.2 \mathrm{M}, \mathrm{pH} 6.6)$ and $1 \mathrm{~mL}$ of potassium ferricyanide solution (1\%).The resulting solution was incubated at $50^{\circ} \mathrm{C}$ for 20 minutes. Then $1 \mathrm{~mL}$ of trichloroacetic acid $(10 \%)$ was added to terminate the reaction and was quenched under running water for 5 minutes, the resulting mixture was 
centrifuged at $3000 \mathrm{rpm}$ for 10 minutes. An aliquot of $2 \mathrm{ml}$ was then removed from the top layer of each solution, to which were added $2 \mathrm{~mL}$ of distilled water and $0.4 \mathrm{~mL}$ of ferric chloride solution $(0.1 \%)$. The solution absorbance was measured at $700 \mathrm{~nm}$. Increasing absorbance of the reaction mixture indicates increasing reducing power. Results were expressed as a mean \pm standard deviation (SD) of 5 replicate measurements, with ascorbic acid and butylated hydroxytoluene (BHT) as a reference reducing agent.

\subsubsection{DPPH radical scavenging activity}

The method is based on the purification of DPPH by adding radical particles or an antioxidant that discolor the DPPH solution [17]. The degree of colour change is proportional to the concentration and efficiency of the antioxidants. Antioxidant activity is then measured by the decrease in absorption at $517 \mathrm{~nm}$. Dry extract (RE) was dissolved in ethanol at various concentrations ranging from 0.01 to $0.5 \mathrm{mg} / \mathrm{ml}$. Each dilution $(0.5 \mathrm{ml})$ was mixed with $3 \mathrm{ml}$ of an ethanolic solution of DPPH $(0.1 \mathrm{mmol})$. The mixture was incubated in the dark at room temperature and the absorbance of the DPPH solution was measured at $\lambda=517 \mathrm{~nm}$ (Jasco V-530, Japan) to and 30 minutes after adding the extract (sample). In the blank, ethanol was used in place of the sample. Ascorbic acid and gallic acid, BHT were used as a positive control.

\subsection{Surface morphology studies (SEM \& AFM analysis)}

The AFM analysis was performed in tapping mode using AFM (Dimension Icon ScanAsyst) supported by NanoScope V having spring constant of $42 \mathrm{~N} / \mathrm{m}$ and tip radius $10 \mathrm{~nm}$. The measurements were done at room temperature and a scan rate of $0.4 \mathrm{~Hz}$ over an area of $50 \times 50 \mu \mathrm{m}^{2}$ [22]. The morphologies of mild steel surfaces after 20 days of immersion in chloride solution $(0.5 \mathrm{M} \mathrm{NaCl}$ solution) without and with the presence of plants extract were examined by scanning electron microscope. The surface morphology and coating were examined by FEI E-SEM XL 30 (Detection of secondary electrons). For SEM images, $1 \mathrm{~cm}^{2}$ sample was taken.

\subsection{Weight loss measurements}

For weight loss estimations the mild steel specimens were set up as ASTM G 31-72 [23]. Mild steel coupons of dimensions $5.0 \times 3.0 \times 0.2 \mathrm{~cm}$ were used in the weight loss experiments. Before each experiment, the coupons were abraded and polished using emery papers (grades 220-1200), washed thoroughly with distilled water, degreased with acetone and finally dried. The initial weight of each coupon was taken (before immersion) using an analytical balance. Then, the specimens were immersed in $0.5 \mathrm{M} \mathrm{NaCl}$ solution without and with different concentrations of the apricot pomace extract. After the immersion period, the specimens were taken out, washed, dried and weighed again. The difference in weight was calculated from the initial and final weight of the specimens. All the experiments were performed in triplicate and the average weight loss values were recorded. 
Three values were obtained by repeating experiments three times, and an average value was recorded. Average values of the weight loss data were used in corresponding calculations.

\subsection{Electrochemical measurements}

Electrochemical experiments were carried out in the conventional three-electrode cell with a platinum counter electrode (CE), a saturated calomel electrode (SCE) coupled to a fine Luggin capillary as the reference electrode (RE) and a working electrode (WE). The carbon steel working electrode was designed with a fixed exposed surface area of $0.385 \mathrm{~cm}^{2}$. For the electrochemical experiments, the surface area of the platinum counter electrode is larger than that of WE, and the $\mathrm{CE}$ is countered to the total exposed surface of WE. Thus, the electrical field distribution could be uniform. All electrochemical measurements were carried out using a PARSTAT 2273 advanced electrochemical system (Princeton Applied Research). In order to minimize ohmic contribution, the tip of the Luggin capillary was kept close to WE. Experiments were carried out in duplicate to ensure reproducibility of results. At the beginning of the tests, the working electrode was immersed in the test solution for $1 \mathrm{~h}$ to get a stabilized open circuit potential.

The linear polarization technique (LPR) was applied to study time variation of the corrosion rate $[24,25]$. Polarization resistance values $R_{\mathrm{p}}$ for each probe were measured automatically every $15 \mathrm{~min}$ in a galvanostatic mode. $R_{\mathrm{p}}$ was determined as a quotient of the potential response to the applied current. The density of polarizing current was $i=5 \mu \mathrm{A} / \mathrm{cm}^{2}$. The conventional $B$ value of $26.1 \mathrm{mV}$ was used to obtain the corrosion rate (mm/y) from measured $R_{\mathrm{p}}$ values. This $B$ value is commonly used in neutral water solutions. Data for three probes were averaged.

\subsection{Quantum chemical studies}

Optimization of molecular structure was performed by using the HyperChem 8.0 programming. At the preliminary stage of calculations, the geometries of parent molecules in the gas phase have been first optimized using the semi-empirical PM3 method implemented in the HyperChem 8 program package. Next, the energy of the obtained conformers was minimized using the MM+ force field and PM3 parameterizations within the restricted Hartree-Fock (RHF) formalism. The optimized structures which had the minimum energy values were selected for further calculations. Key parameters, for example, the energy of LUMO ( $\left.E_{\text {LUMO }}\right)$, HOMO $\left(E_{\text {Hомо }}\right)$, the energy gap $(\Delta E)$ between LUMO and HOMO, electronegativity $(\chi)$, softness $(\sigma)$ and the hardness $(\eta)$ of the molecules were taken from those optimized structures in a gas phase. It has been suggested that the theoretical calculations the gas phase are a useful method because the results obtained in the gas phase show no significant variation from those obtained in aqueous phase [26-31]. 


\section{Results and discussion}

The results of phytochemical analysis of the EtOH apricot pomace extract are given in Table 1 (see Table 1) and the GC-MS spectrum is shown in Figure 1. As a result of the GC-MS analysis, 41 phytochemical compounds were identified in the apricot pomace extract [32]. This result indicates that APE contains different classes of organic substances in their composition, which can act as corrosion inhibitors. The maximum amount of the component present in APE are: 3,4,5-trihydroxybenzoic acid (Gallic acid) (4.19 percent), chlorogenic acid (3.82 percent), 3-(3,4-dihydroxyphenyl)-2-propenoic acid (caffeic acid) (2.71 percent), 2-(3,4-dihydroxyphenyl)-3,5,7-trihydroxy-4H-chromen-4-one (quercetin) (7.1 percent), catechin (2.94 percent).



Figure 1. GC-MS spectral chromatogram of apricot pomace extract (APE).

According to the chromatogram, five aldehydes are identified by GC-MS in the APE, namely, hexanal (1.28 percent), benzaldehyde (3.18 percent), heptanal (0.64 percent), 2,6,6-trimethylcyclohexene-1-carbaldehyde $\quad(\beta$-cyclocitral) (3.24 percent), 2-phenylacetaldehyde (1.73 percent), terpene alcohols (27.8 percent) and saturated and unsaturated fatty acids (18.91 percent) represented by $(9 Z, 12 Z)$-octadeca-9,12-dienoic acid (linoleic acid), hexadecanoic acid, 1-tetradecanoic acid, octadecanoic acid. All individual chemical compounds are known as inhibitors for several metals [33,34]. The effect of 2-phenylacetaldehyde and hexanal on the corrosion behavior of steel was studied [35] through weight loss, electrochemical, SEM, AFM, quantum chemical calculation methods. It was found that the inhibition effect of 2-phenylacetaldehyde was associated with layerby-layer mechanism formation of a protective film. Interestingly, the electrochemical and spectroscopic studies have revealed that unsaturated aldehydes (2-phenylacetaldehyde) and 
phenolic compounds (thymol and carvacrol) can polymerize on metallic surfaces and show excellent corrosion protection [33-35].

Table 1. GC-MS analysis result of APE.

Holding time $t$, min

\begin{tabular}{|c|c|c|}
\hline 5.34 & (Z)-3-Hexenol & 0.8 \\
\hline 6.81 & 3,4,5-Trihydroxybenzoic acid (gallic acid) & 4.19 \\
\hline 7.23 & 2-Hexanone & 1.05 \\
\hline 7.69 & Mannose & 0.24 \\
\hline 8.01 & 3-Hexanone & 1.72 \\
\hline 9.58 & Hexanal & 1.28 \\
\hline 10.06 & Benzaldehyde & 3.18 \\
\hline 11.96 & Heptanal & 0.64 \\
\hline 12.71 & Phenylacetaldehyde & 1.73 \\
\hline 14.01 & (E)-2-Hexenyl acetate & 1.06 \\
\hline 14.12 & $\begin{array}{c}(1 S, 3 R, 4 R, 5 R)-3-\{[(2 E)-3-(3,4-D i h y d r o x y p h e n y l) p r o p-2- \\
\text { enoyl]oxy }\}-1,4,5 \text {-trihydroxycyclohexanecarboxylic acid } \\
\text { (chlorogenic acid) }\end{array}$ & 3.82 \\
\hline 14.37 & 5-Butyloxolan-2-one ( $\gamma$-octalactone) & 0.71 \\
\hline 14.43 & $\begin{array}{l}\text { endo-1,7,7-Trimethyl-bicyclo[2.2.1]heptan-2-ol } \\
\text { (isoborneol) }\end{array}$ & 0.43 \\
\hline 14.58 & 5-Methyl-2-(propan-2-yl)phenol (thymol) & 3.56 \\
\hline 14.92 & $\begin{array}{c}\text { 2,6,6-Trimethylcyclohexene-1-carbaldehyde } \\
\text { ( } \beta \text {-cyclocitral })\end{array}$ & 3.24 \\
\hline 15.74 & 3-(3,4-Dihydroxyphenyl)-2-propenoic acid (caffeic acid) & 2.71 \\
\hline 15.86 & (Z)-3,7-Dimethyl-2,6-octadien-1-ol (nerol) & 3.09 \\
\hline 16.74 & $\begin{array}{c}(9 Z, 12 Z, 15 Z)-9,12,15 \text {-Octadecatrienoic acid } \\
(\alpha-\text {-linolenic acid })\end{array}$ & 1.94 \\
\hline 16.98 & $\begin{array}{c}(2 R, 3 S, 4 R, 5 R)-2,3,4,5,6 \text {-Pentahydroxyhexanal } \\
(D \text {-glucose })\end{array}$ & 0.98 \\
\hline 17.06 & (2E)-3,7-Dimethyl-2,6-octadien-1-ol (geraniol) & 3.49 \\
\hline 17.29 & (9Z,12Z)-Octadeca-9,12-dienoic acid (linoleic acid) & 3.29 \\
\hline 18.24 & Hexadecanoic acid (palmitic acid) & 2.61 \\
\hline 18.32 & 3,7-Dimethylocta-1,6-dien-3-ol (linalool) & 3.32 \\
\hline 18.94 & 1-Tetradecanoic acid & 3.29 \\
\hline
\end{tabular}




\begin{tabular}{|c|c|c|}
\hline Holding time $t$, min & Name of the compound & Weight ratio, (\%) \\
\hline 19.60 & Octadecanoic acid (stearic acid) & 5.71 \\
\hline 19.62 & (9Z)-Octadec-9-enoic acid & 4.01 \\
\hline 20.67 & $\begin{array}{l}\text { (7a } R)-5,6,7,7 \mathrm{a}-\text { Tetrahydro- } 4,4,7 \mathrm{a} \text {-trimethyl-2(4H)- } \\
\text { benzofuranone }\end{array}$ & 2.04 \\
\hline 21.09 & (Z)-3-Hexenyl butanoate & 2.91 \\
\hline 22.18 & $\begin{array}{l}(1 R, 2 S, 6 S, 7 S, 8 S) \text {-8-Isopropyl-1,3- } \\
\text { dimethyltricyclo[4.4.0.0]dec-3-ene }\end{array}$ & 3.09 \\
\hline 23.07 & $\begin{array}{c}\text { 2-(3,4-Dihydroxyphenyl)-3,5,7-trihydroxy-4H-chromen- } \\
\text { 4-one (quercetin) }\end{array}$ & 7.1 \\
\hline 23.08 & $\begin{array}{l}\text { 3-Cyclohexen-1-ol, 4-methyl-1-(1-methylethyl) } \\
\text { (4-terpineol) }\end{array}$ & 6.24 \\
\hline 23.54 & 2-(4-Methylcyclohex-3-en-1-yl)propan-2-ol ( $\alpha$-terpineol) & 6.61 \\
\hline 23.82 & $\begin{array}{c}\text { (3E)-4-(2,6,6-Trimethylcyclohex-1-en-1-yl)but-3-en-2- } \\
\text { one ( } \beta \text {-ionone) }\end{array}$ & 0.47 \\
\hline 24.16 & $\begin{array}{c}(2 R, 3 S) \text {-2-(3,4-Dihydroxyphenyl)-3,4-dihydro- } 2 H \text { - } \\
\text { chromene-3,5,7-triol (catechin) }\end{array}$ & 2.94 \\
\hline 24.48 & $\begin{array}{l}\text { (2E)-3-(4-Hydroxyphenyl)prop-2-enoic acid } \\
\text { (p-coumaric acid) }\end{array}$ & 1.94 \\
\hline 26.32 & Dihydro-5-octyl-2(3H)-furanone & 0.65 \\
\hline 26.79 & 3,7,11-Trimethyl-1,6,10-dodecatrien-3-ol (nerolidol) & 2.52 \\
\hline 28.44 & 3,3', $4^{\prime}, 5,7$-Pentahydroxyflavone (isoquercetin) & 1.74 \\
\hline 29.51 & Stigmasterol & 0.43 \\
\hline 30.08 & Eicosanic acid & 0.39 \\
\hline 30.92 & $\beta$-Sitosterol & 2.13 \\
\hline
\end{tabular}

The antioxidant activity of the extract was analyzed in several methods because the evaluation of antioxidant properties of plants cannot be carried out accurately by a single universal method. In this study, the antioxidant activity of the ethanol extract was evaluated using 3 different assays.

The total antioxidant activity was measured by phosphomolybdate method. Also, it is a quantitative one, since the antioxidant activity is expressed as the number of the equivalent of ascorbic acid (mg/g plant extract). Extract of cake apricot exhibited concentration-dependent antioxidant capacity with respect to ascorbic acid equivalents (see Table 2). The total antioxidant activity is $460.86 \pm 2.63 \mathrm{mg}$ of AsA/g of the extract. 
Table 2. Characterization of antioxidant activity of the apricot pomace extract.

Total antioxidant capacity (mg ASE/g of the extract)
Reducing power, mg of ASE/g of the extract

Concentration, $\mathrm{mg} / \mathrm{ml}$

\begin{tabular}{lcccccc}
\hline \multirow{2}{*}{$460.86 \pm 2.63$} & 0.5 & 1.0 & 1.5 & 2.0 & 2.5 \\
\cline { 2 - 6 } & 3.3152 & 3.3152 & 3.3152 & 3.3152 & 3.341 \\
\hline
\end{tabular}

This potent antioxidant activity may be attributed to its high phenolic and flavonoid contents. The total antioxidant activity of apricot pomace extract is the result of individual activities of each of the antioxidant compounds present such as tocopherols, carotenoids, and phenolic compounds, the latter being the major phytochemicals responsible for the antioxidant activity of plant materials. Even if a sample exhibits high activity with one of these methods, it does not always show similar good results with all other methods. Therefore, it is essential to evaluate samples accurately by several methods. Reducing power is associated with antioxidant activity and can serve as a significant reflection of antioxidant activity. Compounds with a reducing power show that they are electron donors that have the ability to reduce oxidized intermediates of the processes of lipid peroxidation, they can act as primary and secondary antioxidants. Higher absorbance of the reaction mixture indicates higher reductive potential. Table 2 shows the concentration-absorbance relation for the reducing powers of the extracts. The reducing power of the extracts increased with increase in their concentrations. The extracts exhibited fairly good reducing power. The apricot pomace extract radical scavenging activity was studied by DPPH method using ascorbic acid as the standard and the results are depicted in Table 3. The results indicate the efficacy of the apricot pomace extract in scavenging the DPPH radicals depending on concentration.

Table 3. DPPH radical activity of the apricot pomace extract.

\begin{tabular}{cc}
\hline Concentration, $\mathbf{~ m g} / \mathbf{m l}$ & Percentage of inhibition $(\boldsymbol{\%})$ \\
\hline 0.01 & $33.2 \pm 1.6$ \\
0.05 & $46.1 \pm 1.1$ \\
0.1 & $56.7 \pm 0.9$ \\
0.2 & $68.9 \pm 0.9$ \\
0.5 & $92.6 \pm 0.9$ \\
\hline
\end{tabular}

The antioxidant activity of APE was high (92\%) at $100 \mu \mathrm{g} / \mathrm{mL}$. The radical scavenging activity of this extract is may be due to the involvement of phenolic compounds and also owing to the existence of other antioxidant secondary metabolites like flavonol, terpenoids, tannins etc. [17]. Thus, the analysis of the composition and evaluation 
of the antioxidant properties of the apricot pomace extract indicates that it contains a wide range of organic substances and has a high antioxidant capacity, and therefore is a potential raw material for use as a corrosion inhibitor of metals. The efficiency of various concentrations of apricot pomace extract in $0.5 \mathrm{M} \mathrm{NaCl}$ medium for a period of 26 days obtained via weight loss method is listed in Table 4, indicating that the solution with $500 \mathrm{ppm}$ possessed maximum efficiency for inhibition. The effectiveness of inhibition increased with concentration.

Table 4. Inhibition efficiency and surface coverage (gravimetric data, $624 \mathrm{~h}$ immersion) of mild steel in $0.5 \mathrm{M} \mathrm{NaCl}$ with the inhibitor.

\begin{tabular}{ccc}
\hline $\begin{array}{c}\text { The concentration of the } \\
\text { inhibitor, ppm }\end{array}$ & Inhibition efficiency (IE), \% & Surface coverage, \% \\
\hline 0 & - & - \\
50 & 25.8 & 0.258 \\
100 & 58.9 & 0.589 \\
150 & 68.9 & 0.689 \\
200 & 72.5 & 0.725 \\
250 & 74.2 & 0.742 \\
300 & 78.9 & 0.789 \\
400 & 80.1 & 0.801 \\
500 & 94.6 & 0.946 \\
\hline
\end{tabular}

The reason behind this fact can be given as adsorption of the organic matters of the extracts on the metal surface, which increased the surface coverage area as well as suppressed corrosion reactions rate. However, no significant corrosion inhibition was acknowledged beyond 500 concentrations of the extract, which might be resulted from saturation of inhibitor's adsorption rate on a mild steel surface.

The immersion time is an important parameter in assessing the stability of corrosion inhibitive properties of organic compounds. Figure 2 and Figure 3 illustrates the effect of immersion time on the inhibitive performance of APE. Immersion time was found to have a profound effect on the corrosion inhibition performance by the apricot pomace extract. The formation process of the protective layer can be classified into two steps, namely primary adsorption (1-30 hours) as the first step and then a slow chemical transformation (polymerization) the molecules that were adsorbed on the steel surface (40-48 hours). It is evident from Figure 2 that inhibition efficiency in $0.5 \mathrm{M} \mathrm{NaCl}$ containing APE slowly increased up to the moment when it reached $30 \mathrm{~h}$ of immersion, and then it rapidly increased between $40 \mathrm{~h}$ and $48 \mathrm{~h}$ of immersion till reached its saturation. According to the results above, the maximum inhibition efficiency (about 97\%) was obtained at $500 \mathrm{ppm}$ APE extract after $48 \mathrm{~h}$ immersion. This may suggest that these optimal conditions allow 
the extract molecules to be adsorbed on the steel, forming a thin and uniform film. This suggested that the corrosion protectiveness of APE film-forming on the steel surface was enhanced by prolonging the APE treatment.

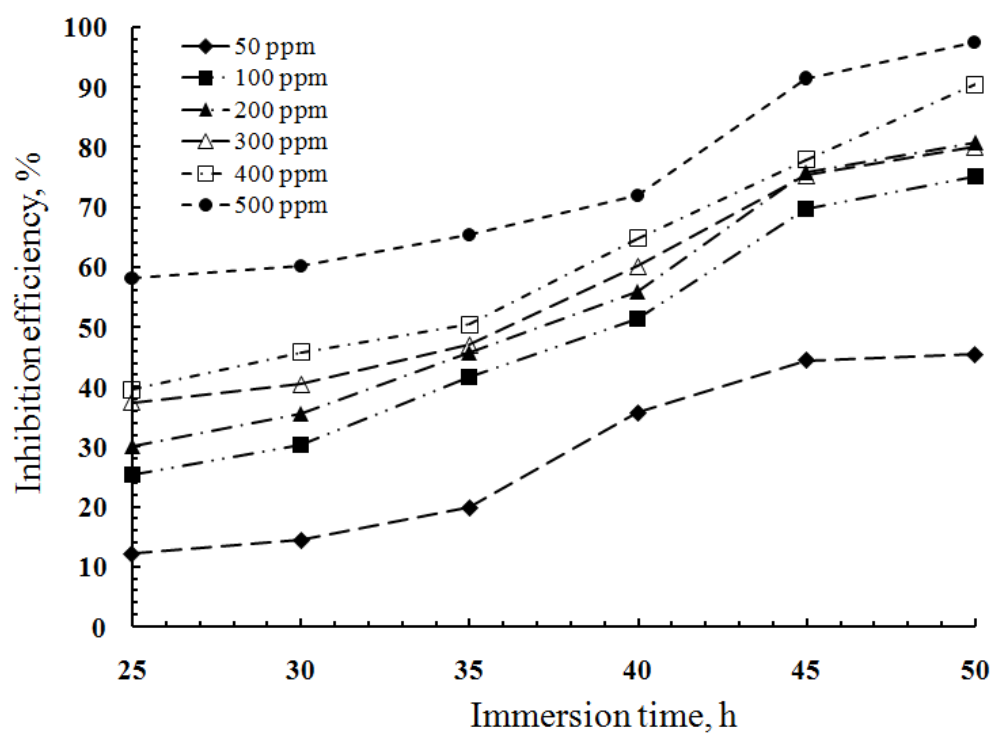

Figure 2. The relationship between inhibition efficiency and immersion time mild steel in $0.5 \mathrm{M} \mathrm{NaCl}$ solution with 50-500 ppm APE.

The effect of immersion time in a $0.5 \mathrm{M} \mathrm{NaCl}$ solution with APE on the weight loss rate indicated that APE not only keeps its inhibitive activity for steel but also improves its effectiveness over the long-term immersion due to the synergistic influence of the main compounds which offer an additional protection.

The relatively poor protection afforded by apricot pomace extract on steel at the initial immersion compared to the results obtained at longer exposure suggests that the formation of a highly protective and stable inhibitor layer on steel surface might need more time than 1-30 h to evolve completely. Similar results were obtained for steel corrosion inhibition by grape and rape pomace extracts in conditions of periodic condensation of moisture [35-41]. When the immersion time was prolonged beyond $210 \mathrm{~h}$, a decrease of the stability of the protective layer was observed as result of desorption of APE molecules and/or diffusion process through the interface protective layer/electrolyte (see Figure 3).

Therefore, on the basis of the immersion time results, one can note the excellent inhibition properties of APE after $48 \mathrm{~h}$ of immersion in the chloride-containing medium and one can suggest that the adsorption mechanism on the carbon steel surface involves two types of interactions, chemisorption and physisorption.

The anodic and cathodic polarization behavior of various immersion times in the inhibitor was studied by the potentiodynamic polarization technique. The polarization curves are shown in Figure 4. The anodic and cathodic corrosion current density curves in presence of inhibitors are shifted towards lower current density region as compared to the 
blank. This reveals that the inhibitors decrease the corrosion current and thus reduce the corrosion rate. The presence of protective film on the surface that formed in solution with apricot pomace extract result marked a shift in the cathodic branches and to a lesser extent in the anodic branches of the polarization curves. Thus the inhibitors are said to be mixed type, but predominantly cathodic. Probably, the organic moieties of apricot pomace extract adsorbed on the metal surface and increased insulating behavior of modified mild steel electrode, which caused lowering in corrosion current values.



Figure 3. Effect of change in immersion time on inhibition efficiency of APE for the steel in $0.5 \mathrm{M} \mathrm{NaCl}$ solution with $50-500 \mathrm{ppm}$ of APE.

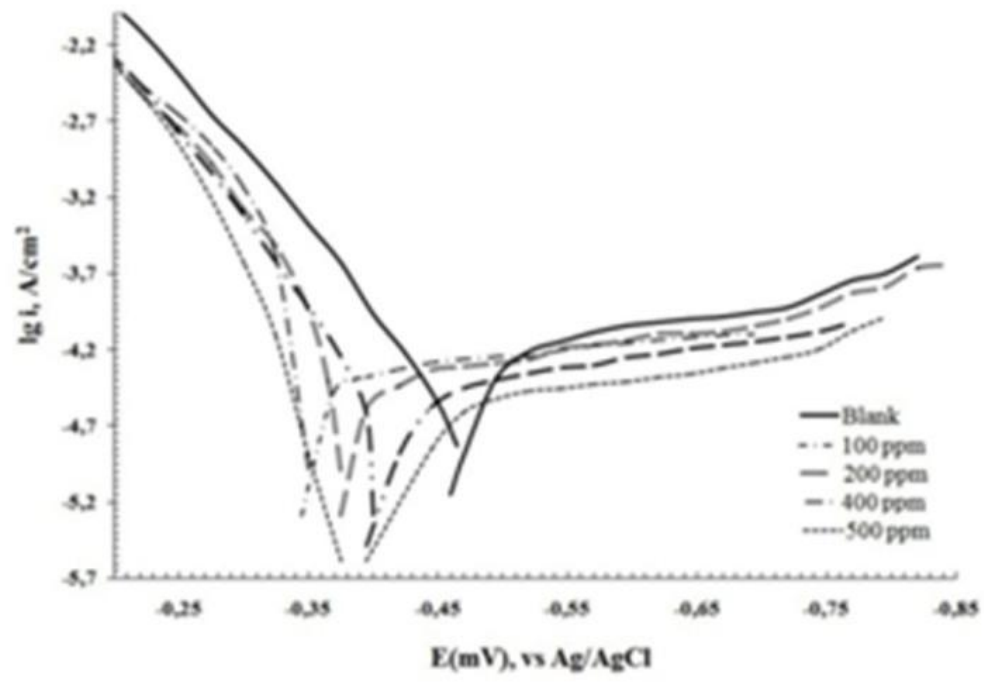

Figure 4. Potentiodynamic polarization curves for mild steel in $0.5 \mathrm{M} \mathrm{NaCl}$ with $0-500 \mathrm{ppm}$ concentration of apricot pomace extract. 
LPR technique was used to investigate the time dependence of corrosion rate during immersion in inhibited and non-inhibited solutions. The corresponding dependences are given in Figure 5.

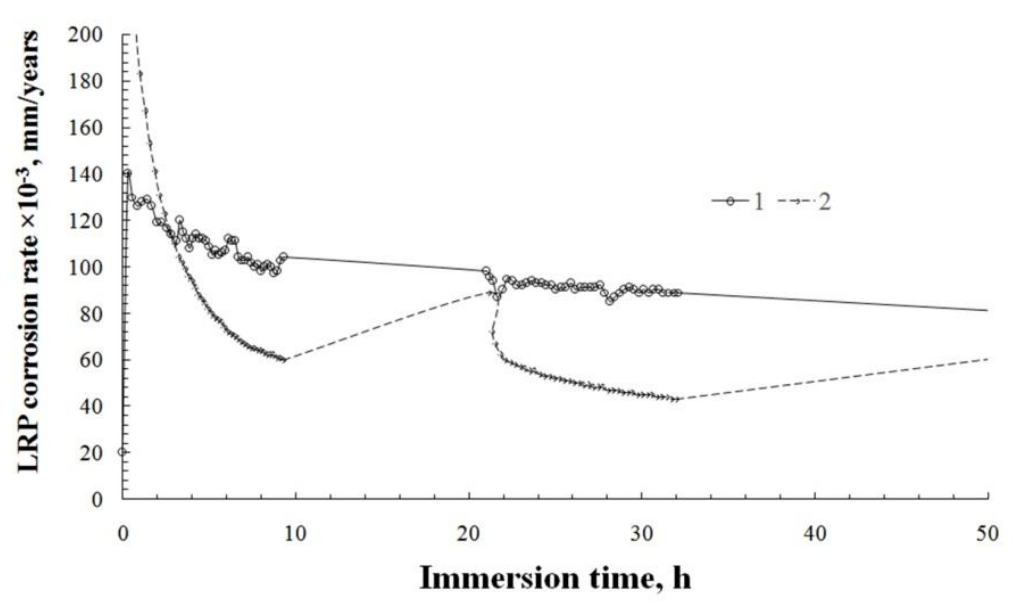

Figure 5. LPR corrosion rate of mild steel St3 in $0.5 \mathrm{M} \mathrm{NaCl}$ solution (1) and with apricot pomace extract (2).

Figure 5 depicts the corrosion rate $(\mathrm{mm} /$ year) for the electrode in $0.5 \mathrm{M} \mathrm{NaCl}$ saturated with inhibitor. Figure 5 shows that the values of corrosion rate are lower with the addition. The same behavior was shown in the case of the evolution of inhibition efficiency in function of immersion time (Figure 5). Such time dependence means that the formation of a barrier layer on the surface is a continuous process which requires at least 25-30 hours. The results obtained from weight loss and potentiodynamic polarization are in good agreement, and the compounds inhibition action could be proved by surface SEM and AFM images. It is well-known that FTIR spectroscopy is a powerful technique that can be used to determine the type of bonding of organic inhibitors absorbed on the metal surface (see Figure 6).

In the present study, FTIR spectra were used to support the fact that corrosion inhibition of mild steel in neutral media is due to the adsorption of inhibitor molecules on the mild steel surface and formation self-transformed the protective films. Fourier transform infrared spectroscopy was used to identify the functional groups and the structural units of the APE components. The FTIR spectroscopy of APE is shown in Figure 6. The bands at $2858 \mathrm{~cm}^{-1}$ and $1505 \mathrm{~cm}^{-1}$ are characteristic of $\mathrm{C}-\mathrm{H}$ and $\mathrm{C}=\mathrm{C}$ stretching vibrations, respectively. The bands below $920 \mathrm{~cm}^{-1}$ are characteristic of $\mathrm{C}-\mathrm{H}$ bending vibrations. The presence of aliphatic $\mathrm{CH}_{3}$ and $\mathrm{CH}_{2}$ groups is indicated by absorption peaks at the 2930-2850 $\mathrm{cm}^{-1}$ (valence vibrations of $\mathrm{CH}_{3}$ and $\mathrm{CH}_{2}$ groups) and in the region of $1463-1377 \mathrm{~cm}^{-1}$ (deformation vibrations). The band at $1452 \mathrm{~cm}^{-1}$ can be attributed to $\mathrm{C}=\mathrm{C}-\mathrm{C}$ aromatic ring stretching. A number of peaks in the $950 \mathrm{~cm}^{-1}$ region indicate the vibrations of the $\mathrm{CH}$ bonds. There are also absorption bands in the range of $1611-1617 \mathrm{~cm}^{-1}, 1505$ and $3400 \mathrm{~cm}^{-1}$, characteristic for vibrations of aromatic structures. 
The peak centered at $1748 \mathrm{~cm}^{-1}$ is attributed to the stretching vibration of $\mathrm{C}=\mathrm{O}$. These observations clearly reveal that the APE is composed of many chemical compounds with hydroxyl, carboxylic and carbonyl functional groups, which may be involved in the mitigation of corrosion through coordination with iron atoms present on the mild steel surface. From the result of immersion, the metal in the solution and the corrosion inhibitor showed a stretch occurring in some organic functional groups. In Figure 6 (2), the FTIR spectrum of steel exposed in $0.5 \mathrm{M} \mathrm{NaCl}$ solution containing extract of apricot cake shows the stretching frequencies shifting to $1786 \mathrm{~cm}^{-1}, 1515 \mathrm{~cm}^{-1}$, and $1711 \mathrm{~cm}^{-1}$ for $\mathrm{C}-\mathrm{H}, \mathrm{C}=\mathrm{C}$, and $\mathrm{C}=\mathrm{O}$ vibrations, respectively. These band shifts confirm that the green inhibitor chemically and/or physically interacts with the metal surface $[38,39]$. The intense band at $1752 \mathrm{~cm}^{-1}$ appeared is characteristic of $v(\mathrm{C}=\mathrm{C})$ groups maybe corresponding to new groups of compounds (dimeric and trimeric polymer adducts) [10,34]. This indicates the possible chemical change of the main compounds of APE once adsorbed on the mild steel surface and explains the highest protection values that achieved only in $48 \mathrm{~h}$. Thus the anticorrosion properties of apricot cake extract cannot be explained only by the antioxidant properties of the molecules contained in these extract [41, 42].
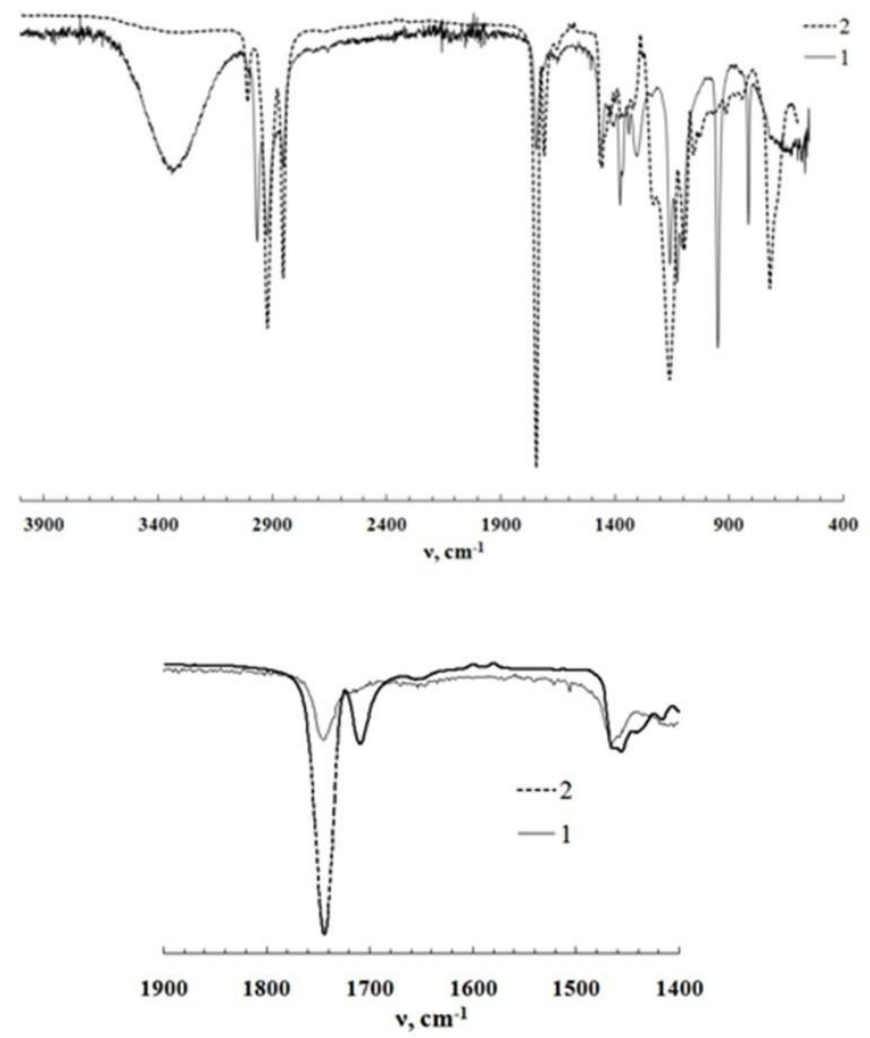

Figure 6. FTIR spectra of apricot pomace extract (1) and mild steel exposed in $0.5 \mathrm{M} \mathrm{NaCl}$ solution containing extract of apricot pomace (500 ppm; pre-treatment immersion time $48 \mathrm{~h}$ ).

SEM analyses were conducted to characterize the protective layer that is formed on the mild steel surface. SEM micrographs (Figure $7 b, c)$ of the steel surfaces in $0.5 \mathrm{M} \mathrm{NaCl}$ 
solutions exhibit the changes which occurred during corrosion process in absence and presence of inhibitor.

a



b

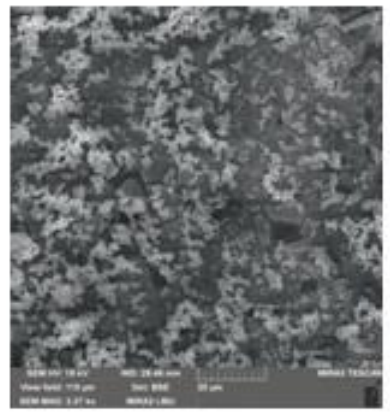

c

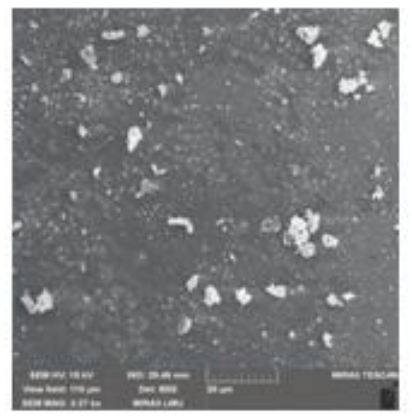

d

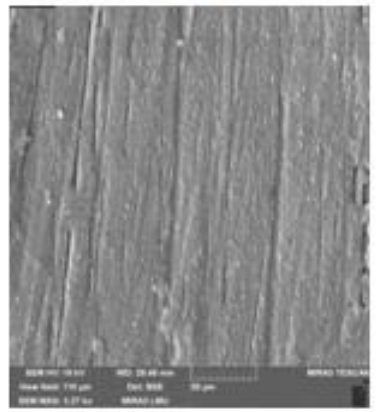

Figure 7. SEM micrographs $(20 \mu \mathrm{m})$ of mild steel polished before immersion (a) and after 96 hours immersion time without inhibitor (b) in $0.5 \mathrm{M} \mathrm{NaCl}$ solution, after 48 (c) and 72 (d) hours immersion with 500 ppm of APE (d).

Close examination of the SEM images reveals that the specimens immersed in the inhibitor-containing solutions possess smoother surfaces compared with the specimens immersed in the blank $0.5 \mathrm{M} \mathrm{NaCl}$ solution, which have corroded, rough, coarse, and uneven surfaces. This observation indicated that the corrosion rate of mild steel was reduced in the presence of the plant extract, which might be due to the formation of a protective adsorbed film on the metal surface. Studies of the morphology of the film at a higher magnification $(500 \mathrm{~nm})$ indicate that the process of a protective layer formation is consistent, and has a layered structure. A similar structure of the film could be formed in the process of partial polymerization of pre-adsorbed compounds of the plant extract and layer-by-layer mechanism formation of a protective film. In addition to SEM, the corrosion samples were examined by AFM as well. The morphology of the film formed in the $0.5 \mathrm{M} \mathrm{NaCl}$ solution with $500 \mathrm{ppm}$ of APE indirectly points on the possibility of polymer transformations of this inhibitor on the metal surface.

The surface morphologies of mild steel specimens under consideration were also investigated using AFM method in order to support the results of other experimental methods. The two-dimensional AFM image of steel before and after immersion in $0.5 \mathrm{M}$ $\mathrm{NaCl}$ without and with 500 ppm of APE is shown in Figure 9.

The abraded mild steel surface is relatively smooth with distinct abrading scratches (Figure 9a,b). After the immersion in $0.5 \mathrm{M} \mathrm{NaCl}$ in the absence of inhibitor, however, the mild surface is highly damaged with deep holes and pits. AFM image analysis was implemented to get average roughness (see Table 5).

The slight roughness $(4.6 \mathrm{~nm})$ was observed on the polished steel surface. The average roughness value for the steel immersed in $0.5 \mathrm{M} \mathrm{NaCl}$ is $115.5 \mathrm{~nm}$. This value suggests that steel immersed in solution of $0.5 \mathrm{M} \mathrm{NaCl}$ has a greater surface roughness than the polished metal surface. This indicates that the unprotected steel surface is rough, 
due to the corrosion of steel in $0.5 \mathrm{M} \mathrm{NaCl}$. In the presence of $500 \mathrm{ppm}$ of ACP, the average roughness decreases to $56.7 \mathrm{~nm}$, confirming the surface appears smoother. The smoothness of the surface is due to the formation of a protective film of APE surfactant on the Fe surface thereby inhibiting the corrosion of steel.
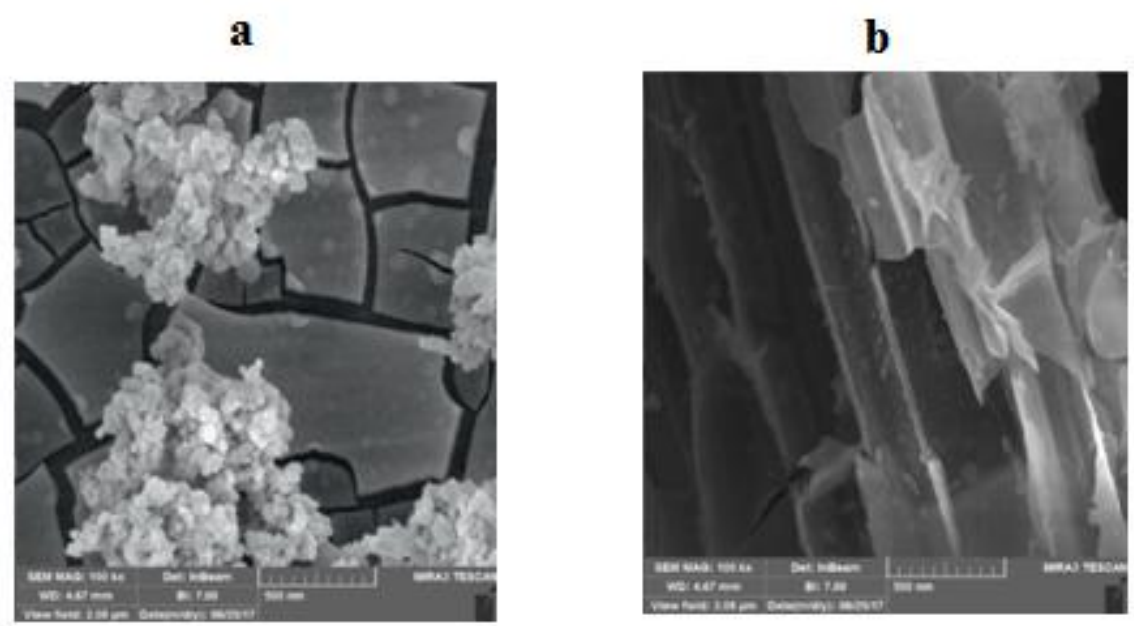

Figure 8. SEM micrographs $(500 \mathrm{~nm})$ of mild steel after 96 hours immersion time without inhibitor (a) in $0.5 \mathrm{M} \mathrm{NaCl}$ solution, after 72 (b) hours immersion with 500 ppm of APE.

Table 5. AFM data for steel surface immersed in inhibited and uninhibited APE solution in $0.5 \mathrm{M} \mathrm{NaCl}$.

\begin{tabular}{cc}
\hline Sample & Average roughness (nm) \\
\hline Polished steel (control) & 4.6 \\
Steel in $0.5 \mathrm{M} \mathrm{NaCl}$ (blank) & 115.5 \\
Blank + 550 ppm APE & 56.7 \\
\hline
\end{tabular}

Molecular structure and electronic characteristics are the key factors in establishing the adsorption ability of inhibitors on a metal surface [26-31]. Quantum chemical calculation was employed to gain insight into the inhibition mechanism of APE by examining the structure-reactivity correlation of the main compounds contained in APE. Figure 10 shows the frontier molecular orbital (FMO) density distributions, i.e., the HOMO and the LUMO. The calculated quantum chemical properties are summarized in Table 6.

From the frontier molecular orbital theory, it is known that transfer of electronic charge at the inhibitor/metal interface is dependent upon the highest occupied molecular orbital (HOMO) and lowest unoccupied molecular orbital (LUMO). The HOMO shows the inhibitor sites with the greatest ability of electron donation, while the inhibitor LUMO is indicative of its regions which accept electrons of the occupied orbitals of metal cations. Thus, a molecule with high-value $E_{\text {Hомо }}$ (HOMO energy) and low-value $E_{\text {Lumo }}$ (LUMO 
energy) has the capacity to donate electrons to vacant orbital for electrophilic attack and accept electron for nucleophilic reaction, respectively.

a

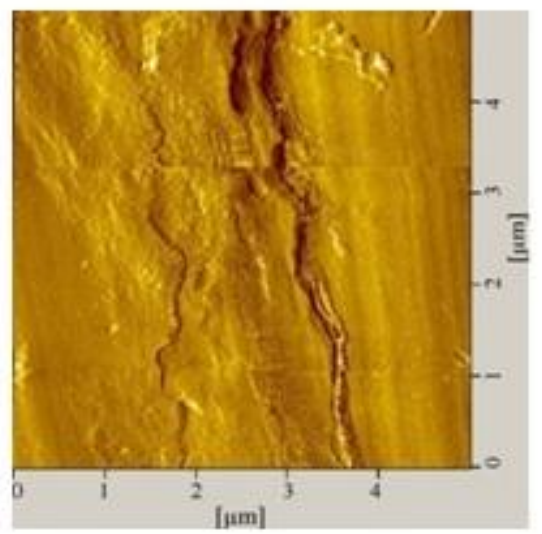

c

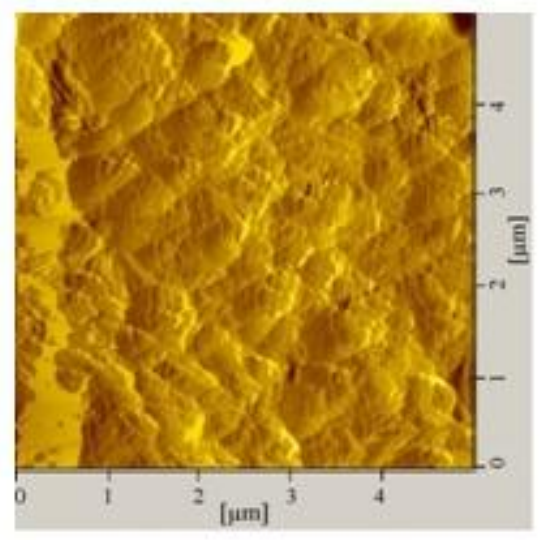

b

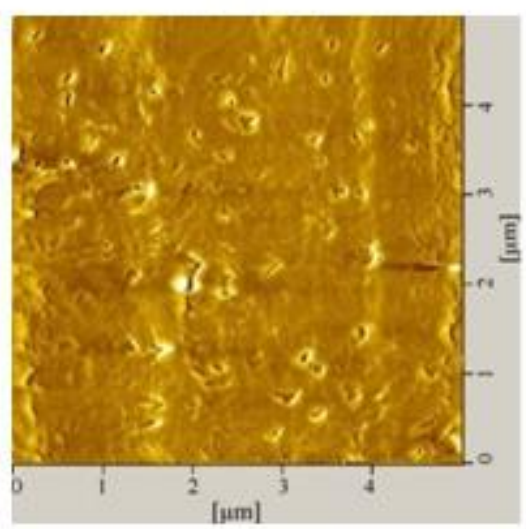

d

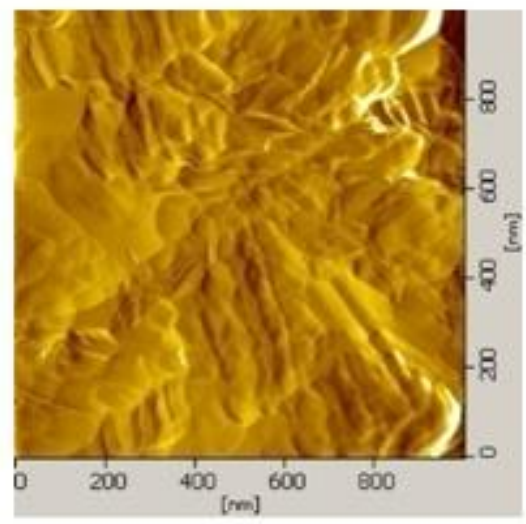

Figure 9. The two-dimensional AFM image of steel before (a) and after immersion in $0.5 \mathrm{M}$ $\mathrm{NaCl}$ without (b) and with $500 \mathrm{ppm}$ of APE (c, d).

The $E_{\text {Hомо }}$ values for compounds increase in the following order: thymol<caffeic acid < catechin < linalool< gallic acid <4-terpeniol < cyclocitral < benzaldehyde.

The analysis in Table 6 demonstrates that cyclocitral and benzaldehyde have near values of $E_{\mathrm{HOMO}}$, which are the highest. This revealed their enhanced electron-donating ability. This suggests that a decreased energy gap of $\Delta E \mathrm{H}-\mathrm{L}$ gives rise to an intensified charge sharing at the interface of inhibitor and metal, which in turn brings about strengthened interactions.

The calculated $\Delta \mathrm{E}$ values of the compounds followed the order of caffeic acid $<$ gallic acid $<$ thymol $<$ catechin $<$ cyclocitral $<$ benzaldehyde $<$ linalool $<4$-terpeniol, indicating that caffeic acid probably played the most prominent role in retarding the corrosion process.

To obtain a clear picture of the interaction between the molecules studied and mild steel surface, intermolecular parameters such as a charge transfer descriptors $(\Delta N)$ and the 
associated energy change $(\Delta E)$ should be taken into account (see Table 7). The electronegativity $(\chi)$ is an indicator of the electron-attraction ability of a molecule. A higher $\chi$ corresponds to a lower chance of electron donationfrom the molecule and vice versa [26-31]. This means higher electronegativity values correspond to higher inhibition efficiencies. According to Table 6, the electronegativity value of the compound increases in order thymol > catechin > caffeic acid > gallic acid > linalool > 4-terpeniol > cyclocitral $>$ benzaldehyde.

All the investigated molecules had electronegativity values lower than $\mathrm{Fe}$ electronegativity $\left(7 \mathrm{eV} \mathrm{mol}^{-1}\right)$.

Hence, the studied molecules are expected to offer electrons to Fe. Moreover, a higher value of global hardness $(\eta)$ indicates a higher resistance of a molecule toward charge transfer [26-31, 41-44]. The calculations indicate that caffeic acid has the lowest value, which means the highest reactivity among the other inhibitor and accordingly the highest inhibition efficiency.

Global electrophilicity index $(\omega)$ informs about the nucleophilic or electrophilic character of the molecule. The higher the value of electrophilicity index, the best the capacity of the molecule to accept electrons. Benzaldehyde has the greatest electrophilicity value $(2.30659 \mathrm{eV} / \mathrm{mol})$, which reflects its nucleophilicity, i.e. its good ability to donate electrons.

Table 6. Calculated quantum chemical properties for the most stable conformations of the major components of the cake apricot extracts.

\begin{tabular}{cccc}
\hline Compounds & $\boldsymbol{E}_{\text {HOMO }}$ & $\boldsymbol{E}_{\text {LUMO }}$ & $\begin{array}{c}\text { HOMO-LUMO gap } \\
(\boldsymbol{\Delta E})\end{array}$ \\
\hline Benzaldehyde & -10.2236 & -0.5566 & 9.6669 \\
Linalool & -9.5938 & 0.8384 & 10.4322 \\
Gallic acid & -9.61154 & -0.7838 & 8.8277 \\
Thymol & -8.83529 & 0.0601 & 8.8954 \\
Cyclocitral & -10.1740 & -0.5268 & 9.6472 \\
Caffeic acid & -9.1764 & -1.11589 & 8.0605 \\
4-Terpeniol & -9.8119 & 0.68560 & 10.4975 \\
Catechin & -9.2143 & -0.1269 & 9.0874 \\
\hline
\end{tabular}

According to Lukovits, if electron fraction transferred $(\Delta N)<3.6$, the chemisorption and inhibition efficiency tendency increases with the increase in the electron-donating ability at the metal surface. 
a

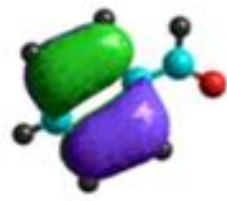

a

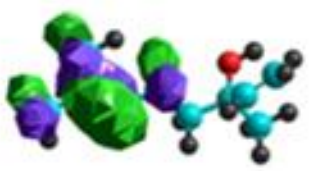

a

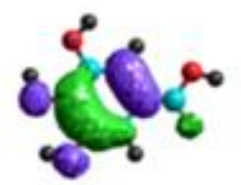

a

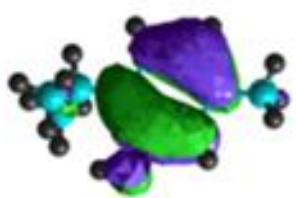

a

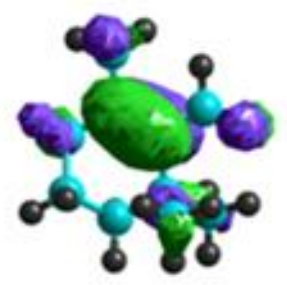

a

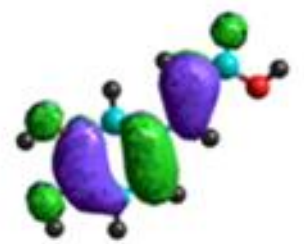

a



a

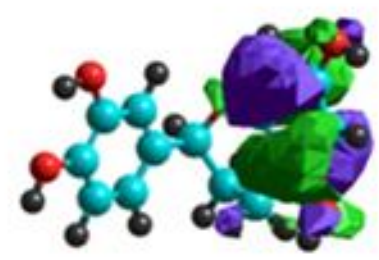

b

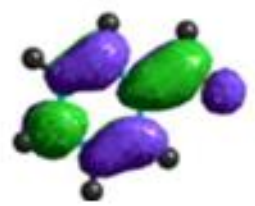

Benzaldehyde

b

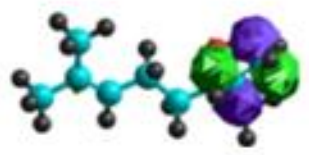

Linalool

b



b

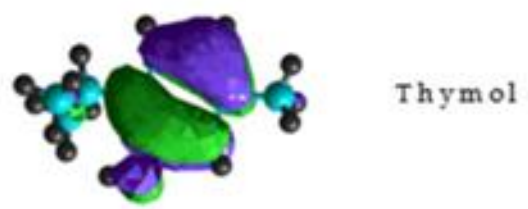

b

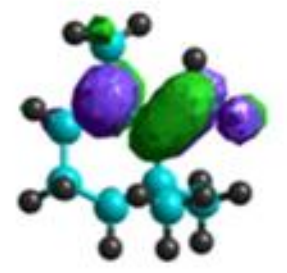

b

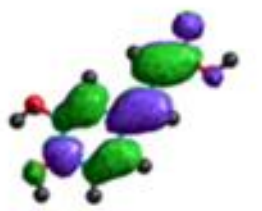

b



Eyclocitral

Caffeic acid

4-terpeniol

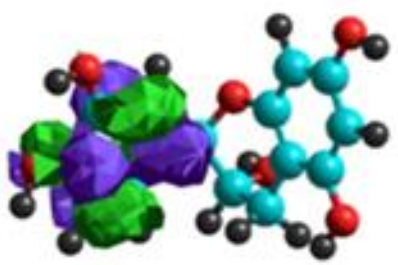

Catechin

Figure 10. The frontier molecule orbital density distributions of studied compounds; highest occupied molecular orbital ( $\left.E_{\text {HOMO }}\right)$ (a) and the lowest unoccupied molecular orbital ( $\left.E_{\mathrm{LUMO}}\right)$ (b). 
Table 7. Calculated quantum chemical properties for the most stable conformations of the major components of the APE.

\begin{tabular}{cccccc}
\hline Compounds & $\begin{array}{c}\text { Electronegativity, } \\
\boldsymbol{\chi}\end{array}$ & $\begin{array}{c}\text { Hardness, } \\
\boldsymbol{\eta}\end{array}$ & $\begin{array}{c}\text { Electrophilicity } \\
\text { index, } \boldsymbol{\omega}\end{array}$ & $\boldsymbol{\Delta N}$ & $\boldsymbol{\Delta} \boldsymbol{E}$ \\
\hline Benzaldehyde & 5.3901 & 4.8334 & 1.3475 & 0.166 & 0.0168 \\
Linalool & 5.2161 & 4.3777 & 1.3040 & 0.203 & 0.0090 \\
Gallic acid & 5.1976 & 4.4138 & 1.2994 & 0.204 & 0.0081 \\
Thymol & 4.3875 & 4.4476 & 1.0969 & 0.293 & 0.0105 \\
Cyclocitral & 5.3504 & 4.8236 & 1.3376 & 0.171 & 0.0146 \\
Caffeic acid & 5.1461 & 4.0302 & 1.2865 & 0.230 & 0.0066 \\
4-Terpeniol & 5.2487 & 4.5631 & 1.3122 & 0.191 & 0.0101 \\
Catechin & 4.6706 & 4.5436 & 1.1677 & 0.256 & 0.0012 \\
\hline
\end{tabular}

All the extract components possess $\Delta N$ values lower than 3.6. This suggested their great tendency to interact with the metal surface. This shows that as the strength of the iron inhibitor bond increases (as a result of increasing $\Delta N$ ), the degree of corrosion inhibition due to chemisorption is increased.

As expected, the most abundant compounds identified in the sample of apricot cake extract contained oxygen atoms with lone electron pairsand aromatic rings with delocalized electrons, which enabled them to adsorb on the metallic surface forming protective layers, which retarded the corrosion process.

\section{Corrosion inhibition explanation}

The presence of such numerous organic compounds makes it rather difficult to attempt to assign the observed corrosion behavior to a particular constituent, but still a possible interpretation of our results may be traced out. The apricot cake extract contains various bioactive molecules, such as flavonoids (10.04 percent) aldehydes (18 percent), terpene alcohols, and acids (18.91 percent). The investigated extract of apricot cake has a high antioxidant activity, which is an indirect evidence of its potentially high anti-corrosion properties. The anticorrosion properties of apricot cake extract, cannot be explained only by the antioxidant properties of the polyphenol molecules, as flavonoids (catechin, quercetin), contained in this extract. In presence of extract, the corrosion rate is actually reduced by the progressive formation of a covering film. This film could be formed by the compounds with unknown antioxidant properties extracted from the apricot cake, but which could be transformed (polymerized) on the steel surface/in solution and cover the steel surface by the film with higher protective properties. In the early stage of immersion (1-20 hours), the formation of a protective layer occurred according to the mechanism of physical adsorption and to the precipitation of more adsorption active compounds. This layer acts a self-protective barrier, characterized low degree of the protective. However at 
increase the time of film forming to $30-50$ hours, the primary protective layer is transformed (polymerized) and other higher molecular weight components of the extract to exhibit the protective effect. A new self-transformed protective layer possesses more high protective properties. In this way, the high inhibitory efficacy of apricot cake extract on steel in neutral solution is the consequence of the formation of the protective film from the main compounds of extract and the products of their chemical transformations on the corroding surface.

\section{Conclusions}

Combining experiments and theoretical calculations, APE has the potential to be developed as an environmentally friendly inhibitor for mild steel corrosion. Characteristics of APE are nontoxic, inexpensive, readily available, and easily extracted. The potentiodynamic polarization studies indicated that APE acts as a mixed-type inhibitor. Weight loss measurements proved a highly protective effect obtained in the presence of APE after several hours of immersion which remains stable over the time. In the investigated experimental condition, the maximum inhibiting efficiency in the range of $94.6 \%$ was obtained by the addition of $500 \mathrm{ppm}$ APE, after about $48 \mathrm{~h}$ of exposure to the inhibitorcontaining electrolyte. The results of the surface analysis performed by SEM and AFM confirm that APE is able to retard the steel corrosion by the formation of a compact and homogeneous surface layer on the metallic surface. Although GC-MS analysis identified the most abundant compounds present in the APE, due to its complex chemical composition, it is difficult to assign the inhibitive effectiveness to a specific constituent. Further studies will focus on the study of the antioxidant and inhibitory properties of the main components of the plant extract, as well as studying the correlation between these two parameters. The results obtained will make it possible to confirm or disprove the importance of the antioxidant properties of the extract, as one of the parameters of the predictive assessment of the inhibitory ability of plant extracts when used as a means of corrosion protection.

\section{References}

1. O.K. Abiola, N.C. Oforka, E.E. Ebenso and N.M. Nwinuka, Anti-Corros. Methods Mater., 2007, 54, no. 4, 219-224. doi: 10.1108/00035590710762357

2. Yu.I. Kuznetsov, Int. J. Corros. Scale Inhib., 2015, 4, no. 4, 284-310. doi: 10.17675/2305-6894-2015-4-4-1

3. G. Vasyliev, A. Brovchenko, and Y. Herasymenko, Chem. Chem. Technol., 2013, 7, no. 4, 477-482.

4. Yu.I. Kuznetsov, Int. J. Corros. Scale Inhib., 2016, 5, no. 4, 282-318. doi: 10.17675/2305-6894-2016-5-4-1

5. Yu.I. Kuznetsov, Int. J. Corros. Scale Inhib., 2017, 6, no. 4, 209-239. doi: $\underline{10.17675 / 2305-6894-2017-6-3-1}$ 
6. Yu.I. Kuznetsov, Int. J. Corros. Scale Inhib., 2017, 6, no. 4, 384-327. doi: 10.17675/2305-6894-2017-6-4-3

7. P.B. Raja and M.G. Sethuraman, Mater. Lett., 2008, 62, no. 1, 113-116. doi: 10.1016/j.matlet.2007.04.079

8. K. Nasr, M. Fedel, K. Essalah, F. Deflorian and N. Souissi, Anti-Corros. Methods Mater., 2018, 65, no. 3, 292-309. doi: 10.1108/ACMM-12-2017-1869

9. S. Javadiana, B. Darbasizadeh, A. Yousefi, F. Ektefa, N. Dalir and J. Kakemam, J. Taiwan Inst. Chem. Eng., 2017, 71, 344-354. doi: 10.1016/j.jtice.2016.11.014

10. G. Vasyliev and V. Vorobiova, Mater. Today: Proc., 2019, 6, no. 2, 178-186. doi: 10.1016/j.matpr.2018.10.092

11. N. Bhardwaj, D. Prasad and R. Haldhar, J. Bio- Tribo-Corros., 2018, 4, no. 4, 61. doi: 10.1007/s40735-018-0178-4

12. T.K. Bhuvaneswari, V.S. Vasantha and C. Jeyaprabha, Silicon, 2018, 10, no. 5, $1793-$ 1807. doi: $10.1007 / \mathrm{s} 12633-017-9673-3$

13. A.S. Yaro, A.A. Khadom and R.K. Wael, Alexandria Eng. J., 2013, 52, no. 1, 129 135. doi: $10.1016 /$ j.aej.2012.11.001

14. A. Saxena, D. Prasad and R. Haldhar, Bioelectrochemistry, 124, 156-164. doi: 10.1016/j.bioelechem.2018.07.006

15. S. Javadian, A. Yousefi and J. Neshati, Appl. Surf. Sci., 2013, 285, 674-681. doi: 10.1016/j.apsusc.2013.08.109

16. J. Gopal, A. Shadma, S. Shanthi and P. Rajiv, Corros. Sci., 2015, 90, 107-117. doi: 10.1016/j.corsci.2014.10.002

17. V.I. Vorobyova, M.I. Skiba, A.S. Shakun and S.V. Nahirniak, Int. J. Corros. Scale Inhib., 2019, 8, no. 2, 150-178. doi: 10.17675/2305-6894-2019-8-2-1

18. V. Oreopoulou and C. Tzia, Antioxidants, and Colorants, 2007, Springer, Boston, MA. doi: $10.1007 / 978-0-387-35766-9 \_11$

19. L.G. Johnsen, P.B. Skou, B. Khakimov and R. Bro, J. Chromatogr. A, 2017, 1503, 57-64. doi: 10.1016/j.chroma.2017.04.052

20. S.E. Stein, J. Am. Soc. Mass Spectrom., 1999, 10, no. 8, 770-781. doi: 10.1016/S10440305(99)00047-1

21. P.M. Pilar and M.A. Pineda, Anal. Biochem., 1999, 269, no. 2, 337-341. doi: 10.1006/abio.1999.4019

22. I. Horcas, R. Fernandez, J.M. Gomez-Rodriguez, J. Colchero, J. Gomez-Herrero and A.M. Baro, Rev. Sci. Instrum., 2007, 78, 013705. doi: $\underline{10.1063 / 1.2432410}$

23. Standard practice for laboratory immersion corrosion testing of metals, G 31-72.

24. H.S. Vasyl'ev, Mater. Sci., 2013, 48, no. 5, 694-696. doi: 10.1007/s11003-013-9556-8

25. Y.S. Herasymenko and H.S. Vasyl'ev, Mater. Sci., 2009, 45, no. 5, 899-904. doi: 10.1007/s11003-010-9256-6

26. S.K. Saha, P. Ghosh, A. Hens, N.C. Murmu and P. Banerjee, Phys. E (Amsterdam, Neth.), 2015, 66, 332-341. doi: 10.1016/j.physe.2014.10.035 
27. V. Vorobyova, O. Chygyrynets', M. Skiba, I. Trus and S. Frolenkova, Chem. Chem. Technol., 2018, 12, no. 3, 410-418. doi: $10.23939 /$ chcht12.03.410

28. V. Vorobyova, O. Chygyrynets, M. Skiba, J. Chem. Technol. Metall., 2018, 53, no. 2, 336-345. https://dl.uctm.edu/journal/node/j2018-2/22_17_91_p_336_345.pdf

29. P. Durainatarajan, M. Prabakaran, S. Ramesha and V. Periasamy, Mater. Today: Proc., 2018, 5, no. 8, 16226-16236. doi: 10.1016/j.matpr.2018.05.114

30. F. Bentiss, B. Mernari, M. Traisnel, H. Vezin and M. Lagrenée, Corros. Sci., 2011, 53, 487-495. doi: 10.1016/j.corsci.2010.09.063

31. S.N. Victoria, R. Prasad and R. Manivannan, Int. J. Electrochem. Sci., 2015, 10, 22202238. http://www.electrochemsci.org/papers/vol10/100302220.pdf

32. S.E. Stein, J. Am. Soc. Mass Spectrom., 1999, 5, no. 10, 770.

33. V. Vorobyova, O. Chygyrynetś, M. Skiba and I. Kurmakova, Int. J. Corros. Scale Inhib., 2017, 6, no. 4, 485-503. doi: 10.17675/2305-6894-2017-6-4-8

34. V. Vorobyova, O. Chygyrynets', T. Overchenko and M. Skiba, Chem. Chem. Technol., 2019, 13, no 2, 261-268. doi: 10.23939/chcht13.02.261

35. V. Vorobyova, M. Skiba and O. Chygyrynets', Pigm. Resin Technol., 2019, 48, no. 2, 137-147. doi: 10.1108/PRT-03-2018-0025

36. O.E. Chyhyrynets' and V.I. Vorob'iova, Mater. Sci., 2013, 49, 318-325. doi: 10.1007/s11003-013-9617-z

37. O.E. Chyhyrynets, Y.F. Fateev, V.I. Vorobiova and M.I. Skyba, Mater. Sci., 2016, 51, 644-651. doi: 10.1007/s11003-016-9886-4

38. V. Vorobyova, O. Chygyrynets', M. Skiba, T. Zhuk, I. Kurmakova and O. Bondar, Int. J. Corros. Scale Inhib., 2018, 7, no. 2, 185-202. doi: 10.17675/2305-6894-2018-7-2-6

39. V. Vorobyova, O. Chygyrynets', M. Skiba, I. Trus and S. Frolenkova, Chem. Chem. Technol., 2018, 12, no. 3, 410-418. doi: $10.23939 /$ chcht12.03.410

40. O.E. Chyhyrynets' and V.I. Vorob'iova, Mater. Sci., 2013, 49, 318-325. doi: 10.1007/s11003-013-9617-z

41. K. Fredy and A.M. Kartika, Prog. Org. Coat., 2015, 88, 256-262. doi: 10.1016/j.porgcoat.2015.07.010

42. X.H. Li, S.D. Deng, X.G. Xie and H. Fu, Corros. Sci., 2014, 87, 15-26. doi: 10.1016/j.corsci.2014.05.013

43. A. Singh, V.K. Singh and M.A. Quraishi, Int. J. Corros., 2010, 1-10. doi: $10.1155 / 2010 / 275983$

44. L. Li, X. Zhang, J. Lei, J. He, S. Zhang, F. Pan, Corros. Sci., 2012, 63, 82-90. doi: $\underline{10.1016 / j . c o r s c i .2012 .05 .026}$ 